\title{
The co-expression of cytokeratin and p63 in epithelioid angiosarcoma of the parotid gland: a diagnostic pitfall
}

\author{
Xu-Yong Lin ${ }^{1,2}$, Yang Liu ${ }^{1,2}$, Yong Zhang ${ }^{1,2}$, Juan-Han Yu ${ }^{1,2}$ and En-Hua Wang ${ }^{1,2^{*}}$
}

\begin{abstract}
Summary: Epithelioid angiosarcoma of the parotid gland is rare, and may pose a great diagnostic challenge. We report a case of primary epithelioid angiosarcoma in a 64-year-old male without history of radiation. The histopathological findings demonstrated a high grade epithelioid neoplasm. Immunostaining showed that the tumor was positive for the pan-cytokeratin, p63, cytokeratin18, Vimentin and vascular markers CD31, and was negative for CD34, cytokeratin5/6, cytokeratin7, cytokeratin20, CD68, CD30, S-100, HMB45, desmin, a-SMA and CD45. The tumor was diagnosed as an epithelioid angiosarcoma. To our knowledge, this is the first reported case of angiosarcoma which showed common positivity for cytokeratin and p63. In addition to cytokeratin, p63 is considered a useful marker for carcinoma. The co-expression of cytokeratin and p63 in epithelioid angiosarcoma represents a diagnostic pitfall. Thus, using a panel of antibodies is essential for distinguishing this tumor from poorly differentiated carcinoma.
\end{abstract}

Virtual Slides: The virtual slide(s) for this article can be found here: http://www.diagnosticpathology.diagnomx.eu/ vs/6548916707504750

Keywords: Angiosarcoma, Cytokeratin, p63

\section{Background}

Angiosarcoma predominantly arises in the skin or superficial soft tissue. The majority of neoplasms of the parotid gland are epithelial, while angiosarcoma, especially epithelioid angiosarcoma is extremely rare [1,2]. Because of its rarity, epitheloid angiosarcoma may be misdiagnosed as an epithelial tumor [3]. Angiosarcoma is a highly aggressive tumor. Local recurrences develop in about one fifth of patients and one half may be expected to die within the first year after diagnosis with metastatic disease in the lung followed by lymph node, bone, and soft tissue [4]. So, it is necessary to distinguish epithelioid angiosarcoma from poorly differentiated squamous cell carcinoma or other epithelioid lesions. Here, we report a case of primary epithelioid angiosarcoma of the parotid gland in a

\footnotetext{
* Correspondence: wangeh@hotmail.com
'Department of Pathology, The First Affiliated Hospital and College of Basic

* Correspondence: wangeh@hotmail.com
'Department of Pathology, The First Affiliated Hospital and College of Basic Medical Sciences, China Medical University, Shenyang 110001, China ${ }^{2}$ Institute of pathology and pathophysiology, China Medical University, Shenyang 110001, China
}

(C) 2012 Lin et al.; licensee BioMed Central Ltd. This is an Open Access article distributed under the terms of the Creative Commons Attribution License (http://creativecommons.org/licenses/by/2.0), which permits unrestricted use, distribution, and reproduction in any medium, provided the original work is properly cited.

\section{Methods}

The resected specimens were fixed with $10 \%$ neutralbuffered formalin and embedded in paraffin blocks. Tissue blocks were cut into 4- $\mu \mathrm{m}$ slides, deparaffinized in xylene, rehydrated with graded alcohols, and immunostained with the following antibodies: pan-cytokeratin (pan-CK), cytokeratin 5/6 (CK 5/6), cytokeratin18 (CK18), p63, vimentin, CD31, CD34, cytokeratin7 (CK7), cytokeratin20 (CK20), S100, desmin, $\alpha$-smooth muscle actin( $\alpha-S M A), C D 45$,

\section{Case history} with a painful swelling of the right parotid gland. The t reported the parotid gland increased rapidly in pital. Three months later, the tumor recurred in the same site, and then the tumor was excised again.

\section{BiolMed Central}

64-year-old Chinese male without history of radiation to the head and neck. 
CD30, CD68, HMB45 and Ki67. Sections were stained with a streptavidin-peroxidase system (KIT-9720, Ultrasensitive TM S-P, MaiXin, China). The chromogen used was diaminobenzidine tetrahydrochloride substrate (DAB kit, MaiXin, China), slightly counterstained with hematoxylin, dehydrated and mounted.

\section{Results}

Grossly, the resected parotid gland tissue measured $3.2 \times 2.8 \times 1.6 \mathrm{~cm}$ with irregular shape, and was not well circumscribed, the cut surface showed grey-red or grey - white in colour with focal hemorrhage. Histologically, the tumor was made up of large round or polygonal epithelioid cells which were predominantly arranged in solid sheets or nests. The area of necrosis and hemorrhage could also be seen easily. There was no area of spindle cells in the whole section. The cells had pale to basophilic copious cytoplasm and vesicular nuclei, prominent nucleoli with significant anaplastic features. Focally, the tumor cells were arranged into gaping vessel-like spaces or sinusoid-like spaces (Figure 1).

Immunohistochemistry showed the tumor cells were diffuse (over $50 \%$ of tumor cells) positive for pan-CK, p63 and Vimentin, CD31 was also strongly expressed in tumor cells. In addition, a focal and weak immunostaining was seen for CK18. The tumor cells were negative for CD34, CK 5/6, CK7, CK20, S100, desmin, $\alpha-S M A$, CD45, CD30, CD68 and HMB45. Ki67 was expressed approximately in $50 \%$ of all tumor cells (Figure 2). According to the morphological and immunohistochemical findings, the tumor was diagnosed as an epithelioid angiosarcoma.

\section{Discussion}

Angiosarcoma predominantly arises in the skin or superficial soft tissue. Less frequently, it can occur in various organs and has been reported in ovary [5], oral cavity [3], small intestine [6], thyroid [7], pleura [8], lung [9], testis $[10,11]$ and parotid $[2,3]$, even in fibroadenoma [12] and phyllodes tumour [13]. Occasionally, it also may be part of dedifferentiated liposarcoma [14] or mixed malignant tumors $[15,16]$. Epithelioid angiosarcoma most commonly involves deep soft tissue. Histologically, epithelioid angiosarcoma predominantly consists of sheets of highly atypical round cells with prominent nuclei, resembling poorly differentiated carcinoma, so, it may cause a great diagnostic confusion [4]. The diagnosis hint of angiosarcoma may be the existence of sinusoid-like spaces or the remarkable necrosis or hemorrhage. Unfortunately, there is a variant in squamous cell carcinoma, namely, pseudoangiosarcomatous cell carcinoma which also shows anastomosing vascular and gland-like spaces mimicking angiosarcoma [17]. So, in addition to histological findings, immunostaining must be used for distinguishing the two entities.

The endothelial cells show reactivity for several markers, including CD31, CD34 and von Willebrand factor (factor VIII). Among them, CD31 is considered the most sensitive and most specific endothelial cell marker. Epithelioid angiosarcoma is positive for CD31, but it is classically negative for CD34. In our case, there was strong and diffuse expression for CD31 in almost all tumor cells, and CD34 expression was absent. So we made the diagnosis of epithelioid angiosarcoma.

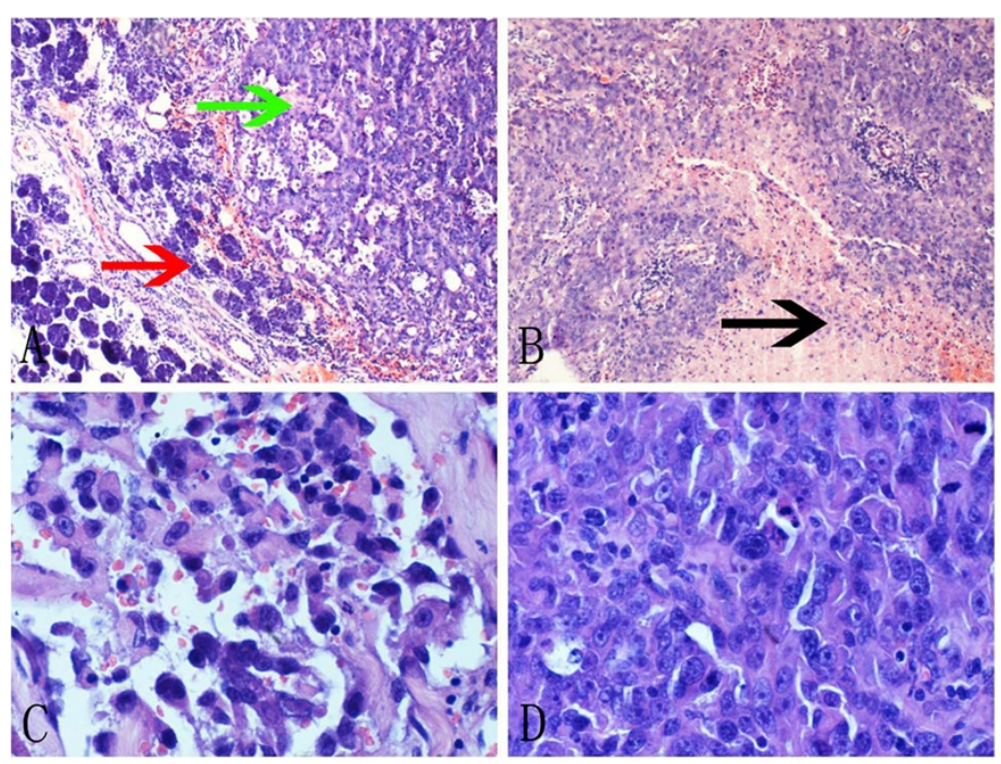

Figure $1 \mathrm{~A}$, The tumor cells were arranged in nests on the right area (green arrow); while the normal parotid gland tissue was on the left area (red arrow). B, The area of necrosis and hemorrhage could also be seen easily (black arrow). C, The large vascular spaces could be seen on peripheral area of the whole section. D, Solid areas showed anaplastic cells with prominent nucleoli and no clear-cut vasoformation. 


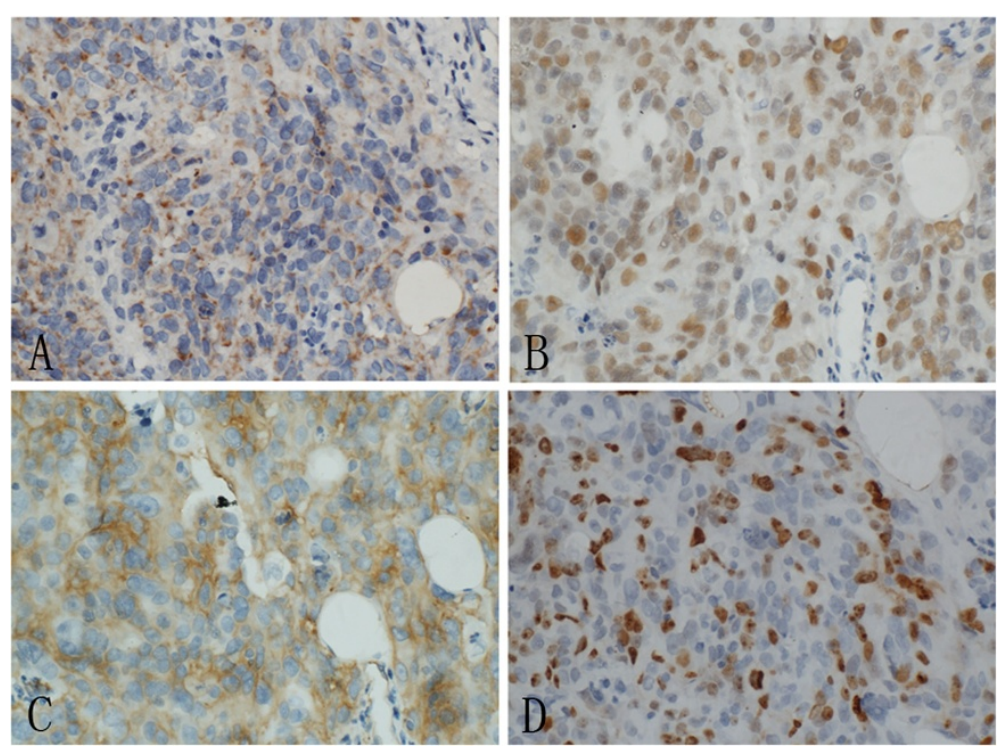

Figure 2 A, Diffuse pankeratin staining highlighted the tumor cells. B, The majority of the tumor cells was positive for p63. C, Diffuse and strong expression of CD31could be seen in the tumor cells. D. Almost 50\% of tumor cells were positive for Ki67.

Some papers have documented that angiosarcoma or epithelioid angiosarcoma can express cytokeratin [18]. Miettinen $\mathrm{M}$ et al. found that epithelioid angiosarcomas were often positive for CK8 and CK18 (approximately 50\%) [18]. Therefore, CK may be not helpful in distinguishing epithelioid angiosarcoma from squamous cell carcinoma. In our case, although CK showed a diffuse expression, but contrary to the diffuse and strong cytokeratin immunoreactivity in most of the carcinoma, the staining seemed to be relatively weak. This may represent an important clue to the possibility of non-epithelial lesions.

P63 is a p53 homolog that is expressed in various normal epithelial tissues and epithelial malignancies $[19,20]$. Many pathologists believed that immunohistochemical staining for p63 protein was a useful marker for distinguishing spindle cell carcinoma from sarcoma [21,22]. Jo VY et al. also demonstrated that p63 immunohistochemical staining is limited in soft tissue tumors, and failed to find expression of P63 in 20 cases of angiosarcomas [23]. On the contrary, in our case we found diffuse p63 expression in the tumor cells. So far, there is only one literature that described the positive expression of p63 in angiosarcoma, that is, Kallen ME et al. reported nuclear p63 expression might been seen in $20 \%-30 \%$ of malignant vascular tumors, including angiosarcoma, epithelioid angiosarcoma and epithelioid hemangioendothelioma [24]. Senoo M et al. found that p63 can affect expression of vascular endothelial growth factor via interactions with hypoxia inducible factor- $1 \alpha$ [25]. Consequently, it is reasonable that p63 can express in vascular tumors, and p63 may not be as specific for the epithelial differentiation as the literatures reported [21-23]. Moreover, in contrast to described by Kallen ME et al. that only a minority of tumor cell nuclei were immunoreactive in most p63-positive vascular tumors [24], in our case over $75 \%$ of the tumor cells was positive. The p63 expression in angiosarcoma represents another diagnostic pitfall.

\section{Conclusion}

Because of the rarity and closely mimicking carcinoma, epithelioid angiosarcoma is misdiagnosed easily, especially when one unfamiliar with this entity. CK and p63 are usually considered as the markers for carcinoma, but our result indicates the co-expression of them can be seen in angiosarcoma, this may be a further diagnostic pitfall. To avoid the misdiagnosis, using a panel of antibodies including endothelial cell markers is quite essential.

\section{Consent}

Written informed consent was obtained from the patient for publication of this case report and accompanying images. A copy of the written consent is available for review by the Editor-in Chief of this Journal.

\section{Competing interests}

The authors declare that they have no competing interests.

\section{Authors' contributions}

LXY participated in the histopathological evaluation, performed the literature review, acquired photomicrographs and drafted the manuscript. LY carried out the immunohistochemical stains evaluation. $\mathrm{ZY}$ and $\mathrm{YJH}$ conceived and designed the study. WEH gave the final histopathological diagnosis and 
revised the manuscript. All the authors read and approved the final manuscript.

Received: 18 June 2012 Accepted: 10 August 2012

Published: 3 September 2012

\section{References}

1. del Rio MJ P, Garcia-Garcia J, Diaz-Iglesias JM, Frasno MF: Radiationassociated angiosarcoma involving the parotid gland. Histopathology 1998, 33:586-587.

2. Fanburg-Smith JC, Furlong MA, Childers EL: Oral and salivary gland angiosarcoma: a clinicopathological study of 29 cases. Mod Pathol 2003, 16:263-271.

3. Terada T: Angiosarcoma of the oral cavity. Head Neck Pathol 2011, 5(1):67-70.

4. Fletcher CDM, Unni KK, Mertens F: World Health Organization classification of tumours: pathology and genetics of tumours of soft tissue and bone. Lyon: IARC Press; 2002

5. Bösmüller H, Gruber C, Haitchi-Petnehazy S, Wagner D, Webersinke G, Hauptmann S: Primary angiosarcoma of the ovary with prominent fibrosis of the ovarian stroma. Case report of an 81-year old patient. Diagn Pathol 2011, 6:65.

6. Delvaux V, Sciot R, Neuville B, Moerman P, Peeters M, Filez L, Van Beckevoort D, Ectors N, Geboes K: Multifocal epithelioid angiosarcoma of the small intestine. Virchows Arch 2000, 437(1):90-94.

7. Maiorana A, Collina G, Cesinaro AM, Fano RA, Eusebi V: Epithelioid angiosarcoma of the thyroid. Clinicopathological analysis of seven cases from non-Alpine areas. Virchows Arch 1996, 429(2-3):131-137.

8. Kao YC, Chow JM, Wang KM, Fang CL, Chu JS, Chen CL: Primary pleural angiosarcoma as a mimicker of mesothelioma: a case report. Diagn Pathol 2011, 6:130

9. Pandit SA, Fiedler PN, Westcott JL: Primary angiosarcoma of the lung. Ann Diagn Pathol 2005, 9:302-304.

10. Masera A, Ovcak Z, Mikuz G: Angiosarcoma of the testis. Virchows Arch 1999, 434(4):351-353.

11. Armah HB, Rao UN, Parwani AV: Primary angiosarcoma of the testis: report of a rare entity and review of the literature. Diagn Pathol 2007, 2:23.

12. Babarović E, Zamolo G, Mustać E, Strčić M: High grade angiosarcoma arising in fibroadenoma. Diagn Pathol 2011, 6:125.

13. Mamoon N, Mushtaq S, Hassan U, Rashid R, Khadim MT, Sarfraz T, Waqar MA: Angiosarcoma arising in recurrent phyllodes tumour. Histopathology 2009, 54:913-916.

14. da Cunha IW, Kowalski LP, Soares FA: Dedifferentiated liposarcoma of the oral cavity with angiosarcomatous dedifferentiation. Virchows Arch 2005, 446(4):456-459.

15. Ryan JF, Kealy WF: Concomitant angiosarcoma and carcinoma of the breast: a case report. Histopathology 1985, 9:893-899.

16. Li YF, Yu CP, Wu ST, Dai MS, Lee HS: Malignant mesenchymal tumor with leiomyosarcoma, rhabdomyosarcoma, chondrosarcoma, and osteosarcoma differentiation: case report and literature review. Diagn Pathol 2011, 6:35.

17. Terada T: Papillary squamous cell carcinoma of the oral cavity with acantholytic and pseudovascular features. Int J Clin Exp Pathol 2011, 4 (8):794-796.

18. Miettinen M, Fetsch JF: Distribution of keratins in normal endothelial cells and a spectrum of vascular tumors: implications in tumor diagnosis. Hum Pathol 2000, 31:1062-1067.

19. Laurikkala J, Mikkola ML, James M, Tummers M, Mills AA, Thesleff I: P63 regulates multiple signalling pathways required for ectodermal organogenesis and differentiation. Development 2006, 133(8):1553-1563.

20. Nekulova M, Holcakova J, Coates P, Vojtesek B: The role of P63 in cancer, stem cells and cancer stem cells. Cell Mol Biol Lett 2011, 16(2):296-327.

21. Dotto JE, Glusac EJ: P63 is a useful marker for cutaneous spindle cell squamous cell carcinoma. J Cutan Pathol 2006, 33(6):413-417.

22. Kurian KM, Al-Nafussi A: Sarcomatoid/metaplastic carcinoma of the breast: a clinicopathological study of 12 cases. Histopathology 2002, 40(1):58-64.

23. Jo VY, Fletcher CDM: P63 immunohistochemical staining is limited in soft tissue tumors. Mod Pathol 2011, 24(15):15A.
24. Kallen ME, Nunes Rosado FG, Gonzalez AL, Sanders ME, Cates JM: Occasional staining for p63 in malignant vascular tumors: a potential diagnostic pitfall. Pathol Oncol Res 2012, 18:97-100.

25. Senoo M, Matsumura Y, Habu S: Ap63y (p51A) and dNp63a (p73L), two major isoforms of the p63 gene, exert opposite effects on the vascular endothelial growth factor (VEGF) gene expression. Oncogene 2002, 21 (16):2455-2465.

doi:10.1186/1746-1596-7-118

Cite this article as: Lin et al:: The co-expression of cytokeratin and p63 in epithelioid angiosarcoma of the parotid gland: a diagnostic pitfall. Diagnostic Pathology 2012 7:118.

\section{Submit your next manuscript to BioMed Central and take full advantage of:}

- Convenient online submission

- Thorough peer review

- No space constraints or color figure charges

- Immediate publication on acceptance

- Inclusion in PubMed, CAS, Scopus and Google Scholar

- Research which is freely available for redistribution

Submit your manuscript at www.biomedcentral.com/submit
() Biomed Central 